\title{
ARQUITECTURA Y URBANISMO DE LA SIMULACIÓN EN TIJUANA
}

\author{
Eloy Méndez Sáinz ${ }^{1}$ \\ Centro de Estudios de Norteamérica \\ El Colegio de Sonora
}

Remisión Artículo: 15-12-2007

Remisión definitiva: 28-1-2008

Palabras clave: arquitectura, simulación, Tijuana, imaginario, frontera.

Resumen: En la solución arquitectónica de la realidad predomina la tendencia a presentarla como imágenes y con ello como simulacro. Para mostrarlo presento la "lectura" de un edificio ordinario en el paisaje urbano de Tijuana, un hotel de paso. El recorrido del lugar da cuenta de los detalles constructivos de un hecho social asumido a la manera de espectáculo, donde los actores involucrados comparten los supuestos de la representación. El caso es un botón de muestra del tejido urbano fronterizo que ofrece al turista y en general al visitante objetos recurrentes de "lo mexicano" encapsulado sobre pedido. Obedece también a la clasificación genérica y maniquea de los espacios del bien y del mal, cuyos referentes respectivos son las ciudades gemelas ubicadas al Norte y Sur de la Línea Internacional. Termino con la versión reciente de la fórmula que pretende consagrar el espacio bueno: el vecindario defensivo.

\section{Introducción}

Parece funcionar la ley del sifón. La delincuencia expulsada de las franjas urbanas de mayor control se traslada a las más desprotegidas. Si bien los vecindarios defensivos suelen ubicar al delincuente fuera de las murallas, ajeno al conjunto de honorables vecinos seleccionados por las inmobiliarias y las fuentes financieras, ello no termina de expulsar las prácticas prohibidas del imaginario ámbito encapsulado. Para confiar en las precauciones del espacio habitado, parece necesario no sólo proveer de recursos visibles de protección, es necesario contar además con un andamiaje de simulación.

El texto se hila con la hipótesis de que la novedosa oferta de vivienda confía en la influencia del entorno edificado sobre el comportamiento de las personas, por lo que se rescata y pone en valor la arquitectura vernácula. El retorno a formas arquitectónicas y urbanas premodernas, la vuelta atrás en el tiempo, se intenta mediante el simulacro: la copia de un modelo imaginario, desconectado de la realidad, es un modelo proveniente de una "realidad" que no existió en el pasado ni existe ahora.

La simulación puede abordarse desde el discernimiento de la disociación de similitud y semejanza. La semejanza consistiría en el parecido a un original. La semejanza es la representación del patrón o modelo que sirve de base. El hecho de asemejarse está siempre en función de algo que se toma como original y rige las comparaciones de todo aquello que se le compare. En cambio, la similitud son series que no parten de original alguno, es la repetición sin principio ni fin. (Foucault, 1981)

Es el simulacro, donde no hay una similitud respecto a un referente fundador aceptado como modelo a imitar ( $A$ se parece a $B$ del mismo modo que $B$ se parece a $A, o$ a $C$, y así). Es decir, con dos ya hay similitud y confusión o inexistencia del modelo que da fe de lo original. Los

\footnotetext{
${ }^{1}$ Persona de contacto Eloy Méndez Sáinz, correo: emendez@colson.edu.mx
} 
signos de la serie se transfieren de una copia a otra, sin el objetivo de representar determinado original: cada ejemplar de una serie se parece al resto de manera indistinta, sin que ejemplar alguno reclame ser el primero, el original y punto de partida.

El simulacro no consiste en falsificar la autenticidad sólo poseída por la naturaleza, según se concebía en el Renacimiento y el Barroco. (Baudrillard, 1992) Ahora no se parte de un original afirmado en seguida gracias a la generación de copias en serie, sino de la reproducción basada en un equivalente donde la serie se cierra y agota en la copia que evidencia la ausencia del original, logrando fundir origen y finalidad en un código genético, lo que certifica a todos los integrantes de la serie como clones de sí mismos, no de un ejemplar "auténtico".

Muchos arquitectos adolecen de la clonación: proyectan y construyen en virtud de lo que importa que aparezca a la vista, sin innovar acorde a los requerimientos sociales, no están dispuestos a involucrarse en propuestas alternativas que les afectarían en la comercialización de sus servicios profesionales y anulan la arquitectura, pues se limitan a complacer los caprichos del cliente de acuerdo con los estándares de moda.

Lo real pervive a través de sus signos en la simulación, cuando el imaginario se desprende de la realidad. En otras palabras, en la realidad se entretejen varias realidades o, si se quiere, el principio de realidad se entrevera con el principio de simulación. Estas prácticas propician la nostalgia por lo originario o, más bien, por los signos que lo aluden, y de ahí el retorno a las soluciones convencionales que evitan lo abstracto, en busca de los referenciales perdidos que la simulación monta para disuadir.

La sociedad actual se ha sumergido en el riesgo global. En el terreno ocular y sensible queda a la supuesta arquitectura sin riesgo jugar el rol central de panacea. La búsqueda compulsiva de seguridad adquiere para Baudrillard tal obsesión que anticipa la muerte en la vida misma: de protección en protección, de defensa en defensa, a través de todas las jurisdicciones, las instituciones, los dispositivos materiales modernos, la vida no es más que una triste contabilidad defensiva, encerrada en su sarcófago contra todo riesgo. (Baudrillard, 1992)

Con la estetización se confunden imaginario y realidad, se pone mayor acento en lo imaginado que en las palabras, se constituye el carácter figurativo de la cultura. El alud imaginario revalora la nostalgia de las formas del pasado, tendiendo a integrar en la ciudad el "simulacro posmoderno", (Fetherstone, 1991) consistente en la rebelión populista que difumina las barreras predispuestas entre la alta cultura y la cultura de masas.

Hay experiencias de espacios singulares que se antojan representativos de los procesos contemporáneos. Uno de ellos, el Centro Pompidou, es concebido por Baudrillard como un modelo de disuasión, "modelo de toda forma de socialización controlada" en el que se expresan los valores del diseño como consenso, polivalencia, visibilidad y transparencia, apostando por la seguridad. Edificio que pretende educar a las masas, es invadido por éstas, fascinadas por la simulación de la cultura mediante artificios arquitectónicos de una transparencia que da al traste con la seducción y por ende con el "intercambio simbólico restringido y altamente ritualizado." (Baudrillard, 2002) La exhibición de las instalaciones confirma la cultura de los hidrocarburos. Al simularse la fácil accesibilidad del contenido detentado por el edificio, la lección del recorrido es sosa, insípida, sin el atractivo de la expectativa dosificada, sin la sensación del descubrimiento progresivo que estimula el trayecto. La apuesta por la seguridad y el control de la visita ha mermado la disposición reflexiva.

Fredric Jameson habla del hotel Westin Bonaventure del centro de Los Ángeles. Destaca que la evolución posmoderna del espacio construido ha seguido un ritmo más veloz que las posibilidades de concebirlo y percibirlo. Portman adopta en el Bonaventure códigos populares antimodernos, no integra el edificio al tejido urbano del entorno, del que pretende dislocarlo, 
afirmarlo como espacio total, sustituto, según luce la inmensa mole cubierta de vidrio que "repele a la ciudad que hay en el exterior." (Jameson, 1996) Sin expresiones audaces de vanguardia a la vista, la industria cultural se vale de arquitectos superestrella para dislocar el paisaje urbano banal mediante estrategias de marketing apoyadas en espacios distintivos. La competencia por el turismo consumidor de espacios "únicos" en boga tiene como única regla romper con todas las reglas, con el propósito de innovar franjas urbanas con exceso de sentido.

En resumen: a) una de las actuales tendencias arquitectónicas es acorde a rasgos figurativos con impronta tradicional, mediante la reedición de arquitectura popular que disuade eliminando los riesgos en actitud preventiva; b) la arquitectura se ubica en el campo de las prácticas orientadas a la manufactura de la hiperrealidad, por lo que tiende a ajustarse al esquema de simulacro a implementar basado en un modelo, y c) este modelo, de raigambre figurativa e historicista, es la matriz de experiencias singulares, la versión de realidad a reproducir.

Según lo anterior, hay ejemplos significativos que condensan la experiencia contemporánea y procede, entonces, destacarlos. El hacerlo abona los rasgos característicos del paisaje urbano emergente. La breve inmersión en Tijuana, es ilustrativa del simulacro local. Las sensaciones que provoca el entorno urbano de Tijuana (más de millón y medio de habitantes, en 2005), no dejan lugar a tonos medios. Es fascinante por el vértigo de la multitud de experiencias que sugiere y por la brutalidad de los excesos. La sucesión y simultaneidad de la multitud de imágenes contrastantes, discontinuas, fragmentarias, quedan en la memoria del transeúnte como retazos de producción cinematográfica. Sacude la ortodoxia ética y estética, al tiempo que seduce. Rica en montajes efímeros, es vital, creativa, dinámica, apabullante, miserable; "horrible", dictaminará con ironía Humberto Félix (Félix, 2003) la riqueza imaginaria y simbólica de la ciudad. Ciudad de paso, de tránsito entre países, posee de origen el carácter de una inmensa yuxtaposición de no lugares, sitios anónimos, o espacios de flujos (Silvestro y Roca, 2007) cuyo arquetipo es la aduana, pero que prolifera en presentaciones de hogares que son más bien alojamientos, expendios de souvenirs, clínicas o consultorios médicos de visita rápida, plantas maquiladoras de estancia imprevisible y ágil rotación de personal, templos de los más diversos credos, yunques -cementerios automotrices- $y$, desde luego, hoteles y cuarterías de migrantes.

La ciudad invita a no conformarse con la "lectura" de primera intención. Por ejemplo, los murales en la Línea internacional pueden entenderse como ataques a la barrera separadora, son a la vez conciliaciones que naturalizan su presencia, una muestra del humor hacia la condición propia, y hasta una forma contradictoria de apropiársela, es también la versión funcional del graffiti transgresor en la barda del aeropuerto al lado; es, en el extremo, el juego visual del muro continuo adaptado por analogía como cinta cinematográfica, revirtiendo el carácter opresor del borde enfatizado con la reutilización de placas metálicas empleadas en la guerra de Oriente. El hecho es que la barda divisoria es subvertida, aligerada con imágenes montadas en secuencias fílmicas pop que resignifican objetos incorporados a la vida cotidiana, objetos ordinarios que al ser puestos en primer plano destacan su individualidad expresiva en formas extraordinarias gracias a la exposición en términos de "continuidad intensificada" (Bordwell, 2004), manera cinematográfica de generar hiperrealidades mediante la "intensificación de las técnicas establecidas".

El resultado es un lienzo kilométrico percibido desde el tráfico automotriz; es un calidoscopio en el que la imagen individual adquiere densidad gracias a la operación paralela de repetición, fragmentación y descomposición; cada imagen es un punto en la textura del amplio tejido urbano. 
En el imaginario fronterizo, la clase política observa relaciones ambivalentes con los narcotraficantes, del mismo modo que la fachada catedralicia compite con los centros nocturnos, clínicas, consultorios dentales y farmacias. Las ofertas de topless, viagra, tequila margarita, artesanías, prostitutas, endodoncias y vida segura contemporizan sin conflicto. Cualquier tienda de curiosidades para turistas se antoja representativa de la ciudad, cápsula concentrada del paisaje urbano o versión momentánea de la ciudad en venta: del mismo modo que la cerámica se ordena puntillosa en un estante, las copas en otro, los zarapes a manera de toldo en el acceso, los trastes de cobre en un rincón, para formar con miles de objetos más el atestado escenario indescriptible, la ciudad ordena edificios a puños en un lado y otro, ofrece un panorama sin sentido, o, si se quiere, la intensidad provocada por demasiados sentidos entreverados, que remite a "la profunda significación del sinsentido de la vida". (Maffesoli, 2004).

El turista sólo podría diferenciar y seleccionar tras horas de observación atenta entre obscuros pasillos atiborrados e incómodos, un verdadero desafío al ánimo de quien va de paso y presuroso a quedarse con curios de "lo mexicano", o una prueba de su estancia fugaz, o la vana aspiración de contener el tiempo en referencias fragmentarias. Quizás es el desorden y el bombardeo de imágenes la explicación con auxilio de los estereotipos: el cuadro del indio impasible con el penacho junto a la india dormida, el campesino de barro con cabeza gacha bajo el enorme sombrero de palma, el Cantinflas desfajado, la pirámide mesoamericana en relieve de cobre, el dominó de ónice, la media luna fundida con el sol radiante y la sarta de chiles de barro. Sólo la convivencia desenfadada con los pequeños absurdos cotidianos explica la foto del improvisado jinete charro sobre el burro maquillado de cebra. Es un tour fácil en el México que el turista quiere ver compacto, barato, empalagoso, reciclable (y reciclado); no conmueve, ni encanta, como tampoco es misterioso y mágico; incentiva la compra descuidada y el gusto complaciente. Las listas inconexas de objetos a la vista son interminables, imágenes acumuladas sin regla de yuxtaposición y sobreposición que subordina a la arquitectura al mismo rol.

El paramento continuo es resuelto en cada caso en forma efímera distinta, obligado para competir con atractivos diferentes. A la vez, la fachada es prescindible, superficie porosa de interiores laberínticos que extienden el espacio liso de la calle, cuyas banquetas son invadidas por mercancías y vendedores. Este entorno de imaginario abrumador se correspondería con las soluciones del espacio habitable. En las ciudades fronterizas, puntos de tránsito por definición, la casa es un punto de paso. Además, este "México autóctono" se repite y se retroalimenta en cada comercio, en cada calle, en cada ciudad; es igual a sí mismo en cada ocasión, con hilos de sujeción en el México de tierra adentro, pero intercambiables, sustituibles y ninguno es más importante que otro.

El paisaje es complejo, abigarrado, enigmático, encaminado a ordenar las ofertas instaladas en galerías lineales sobre los paramentos. Tras la fachada sostenida con alfileres el orden endeble sucumbe en laberintos, del mismo modo que las veredas, casas, ruinas, taludes, adoratorios y basureros de las colonias se confunden en las cañadas sucedidas unas a otras, apenas escanciadas por breves mesetas.

Todo vale. El Hotel Grand Palma Real es botón de muestra. Un hotel de paso en una ciudad de paso, ubicado en una calle de tráfico rápido parecería ocioso, prescindible, o al menos confundido en las intrascendencias de la arquitectura masificada. Y no, no descansa su función en la invitación discreta. La fachada está revestida de exotismos sobrepuestos, yuxtapuestos y hasta mezclados en híbridos arbitrarios. El pavor al vacío no deja resquicio en paz. Todo muro está decorado en actitud barroca sin emplear el lenguaje del barroco. El eslogan del acceso invita al placer y al poder, es una serie de alusiones agresivas, chocantes, explícitas algunas, subliminales otras; el abigarrado conjunto imposibilita contemplaciones donde la reflexión sobra por inoportuna; el fauno petrificado, el león real, la columna potente y la cabeza del puma 
brioso asientan la seguridad erótica del macho cabrío. La salida es el remanso acuático que pretende limpiar resabios, armonizar el breve pasaje con elementos naturales unos y de fantasía sacra otros; los nobles delfines chapotean, la ninfa rodeada de nenúfares y lirios, la desnudez de la diosa egipcia evoca la fertilidad terrena del entorno paradisíaco. Dominantes, la gran cabeza oriental y la pirámide amparan y estabilizan el tinglado, montaje de set hollywoodesco que pone punto final al episodio incorporándolo al bagaje de las imágenes que dan fe de la existencia del encuentro furtivo.

Furtivos somos todos: sería el mensaje a contrarrestar de la ciudad de masas desorganizada y anónima, no negado, sino reducido a la pureza del significado desdramatizado. El intervalo temporal en un espacio intersticial parecería una instalación al margen del entorno urbano llano y de tiempos holgados. Pero si la ciudad real es cúmulo desarticulado de pliegues topográficos y de ritmos compulsivos sujetos a la oferta laboral y de consumo establecida al otro lado de la Línea, los encuentros informales se tornan azarosos, forzados, descargados de virtudes comunicativas y afectivas. Las relaciones convencionales deficitarias incorporan en este contexto las prótesis convenientes para actuar de acuerdo a las circunstancias y salir del paso. Palma Real no es un lugar en especial exótico, no es distinta ni condensa a Tijuana (a Nogales, Juárez, o Matamoros, igual da), es componente singular que supone la simulación breve para volver en seguida a la realidad. Es también uno de los placebos ingeniados para la momentánea reproducción de las reglas de vida sin prótesis y sin red de protección.

Luego, las obsesiones. Redundancias fálicas, tanto como ambivalentes cuerpos entrelazados en las pinturas de las bóvedas, prueban sin compromiso la desnudez del clasicismo, intentan sin mucho esmero el tratamiento subliminal del poder enaltecido como objetivo último, legitimado quizá por la pose "elegante" o "culta". La autorreferencia didáctica al dominio masculino difumina en colores toda deficiencia de género. Hay alusiones masónicas, del kama sutra, del cine -Indiana Jones, Scarface, Casino, The Godfather-, de la heráldica medieval, de los espacios lúdicos clásicos -las termas romanas- y el feng shui. Un fúnebre halcón aguarda en su jaula de hierro negro el suministro de las desnudas crías de ratas exhibidas en jaulas de cristal transparente, espectáculo machista que consagra con sadismo la relación de género, poder y placer, evoca que "lo salvaje y el artificio se alían".

Universo encapsulado cuyas vivencias empiezan y terminan en el punto de acceso y control, es un espacio de uso colectivo, selectivo, constreñido en el marco de reglas privadas. En el punto de salida, la serenidad de la imagen milenaria del remanso petrificado en oscuro tono de metal monocromático, no pretende la reproducción realista de la naturaleza, sino integrarla en el cuadro de las permanencias de las ruinas inmutables gracias al mimetismo del oscuro mundo tecnológico de chatarra oxidada y paisajes pétreos retomados del film futurista Star Wars, cargando de excesos expresivos un punto de paso en principio destinado a ser inadvertido en el diseño de cualquier hotel de paso.

El humor involuntario emerge en escenas que podrían ser sobrecogedoras en otro sitio: la abundancia de símbolos confunde, la manufactura descuidada exhibe las burdas simulaciones rocosas a base de poliuretano y fibra de vidrio, la ausencia de agua de los estanques resalta la apariencia gris de un patético reino olvidado. Pero estos "descuidos" no colapsan la intensidad en el efecto buscado, tampoco evidencian la falta de autenticidad, pues el acuerdo tácito es que se trata de un montaje fílmico, esto es, de simulación, provisorio, de ocasión.

Se pretende organizar y dar sentido a la secuencia de sensaciones en un espacio lúdico autocontenido, donde hay que proveer de los ingredientes necesarios a la eficiente ejecución de los roles de convenidos pendientes entre la actuación y la vivencia real. Tan es esto así, que el bar también está ambientado para que los propietarios y allegados se autorreconozcan en personajes del cine negro que seguro han visto en las pantallas ("¡Veámonos! ¡Cuán terribles somos...!"). Y se cierra el círculo. 
El reto del diseño de Palma Real no es, entonces, disimular un antro empleando el lenguaje inexpresivo del modernismo, con frecuencia empleado décadas atrás para homogenizar los espacios. Tampoco es fingir, ya se veía, que se está en un exótico lugar determinado. Más bien, importa simular un lugar que garantice el despliegue placentero de actuaciones efímeras, donde personajes de ocasión autocomplacientes se observan en roles asignados en escenas imaginarias, apoyadas en muros-espejo que devuelven al observador el objetivo recortado por el obturador de la cámara inexistente.

Esto se logra montando un lugar sin referente real, en la confluencia caprichosa de datos provenientes de espacios y tiempos disímiles. El inexistente libreto de la película social supondría la levedad del pasaje, deben evitarse los riesgos de tomar estos episodios como reales para garantizar el consumo lúdico, rápido, satisfactorio y repetible. Lo minucioso del tratamiento del hotel se reproduce en los comercios del distrito turístico, en las cañadas, en los jardines de los barrios viejos, sugiere que los pliegues más intrincados de la epidermis urbana se someten al escáner de la apropiación social tras generaciones que han batallado para hacer habitables rincones descalificados por las normas urbanísticas.

Nadie asume en el Palma Real la actitud modernista de destacar la unicidad de la obra. Se hace de lado el protagonismo de la forma. Si bien el lenguaje arquitectónico es la clave de la propuesta, escapa a toda norma en el uso. La propuesta es el manejo heterotópico de las formas, que formulan una narrativa apropiada al lugar plural y multidimensional. El paisaje compuesto por multitud de construcciones inacabadas sugiere la vitalidad de una estética ambigua y ubicua entre el proyecto sin terminar, la demolición suspendida y la precariedad de la obra incompleta como principio definitorio de espacios que no tienen plazo fijo para su término.

Ejemplos así proliferan en la frontera. Todas ellas son líneas de intervención efímera por voluntad o circunstancia. Las diferentes formas de intervención esbozadas sirven para organizar le lectura de la nueva ciudad en proceso de realización.

Sabemos que en torno a las ciudades fronterizas se ha bordado una sólida "leyenda negra" que reproduce el estereotipo de la impureza, el pecado, la culpa. Por ende, si seguimos la lógica de la "simbólica del mal", los promotores y sus fuentes ideológicas no han batallado en ubicar las ciudades de la región como espacios del mal. Este punto de partida ético, con larga historia desde los mensajes bíblicos acerca de Sodoma y Gomorra, es adjudicado a las faltas cometidas por sus habitantes, de modo que la ciudad carece de pureza y está marcada por la "mancilla", representada como la "infección casi física que apunta hacia una indignidad casi moral." (Félix, 2003) Tras la culpa, carcome el miedo y los ritos de purificación equívocos dirigidos a borrar, lavar, terminar con la infección aludida por la mancha simbólica de la mancilla, mediante gestos de "quemar, alejar, expulsar, lanzar, escupir, cubrir, ocultar". La diferenciación y distanciamiento de lo impuro se encamina a su exención, con el propósito de lograr "la no-mezcla, la no-suciedad, la no-oscuridad, la no-confusión."

Estos valores simbólicos se incorporan en el vocabulario de lo puro y lo impuro, la mancha es una figura simbólica, cosa construida que es referida a través de la palabra que le denomina y le invoca.

La presencia amenazante de lo impuro despierta la sensación de temor, mas el castigo de la culpa tiende a restablecer el orden. 


\begin{abstract}
En las ciudades norfronterizas mexicanas está establecido el espacio del mal en la medida que el espacio del bien monopoliza por autorreferencia los pares gemelos del lado norte. Mas la ubicuidad de la población y franjas físicas de ciudad a negar, o "castigar", induce a una operación invertida similar a la impuesta por los norteamericanos, el orden purificador se oculta a sí mismo en calidad de libertad y bienestar inaccesible. Por ello no es casual que las imágenes promovidas del estilo de vida aparezcan en tonos neutros, pastel, casi sin sombras, casi planas, una plastificación de la casa sin mácula. Son imágenes pasteurizadas, sin la menor ambivalencia.
\end{abstract}

Según la difusión por medios impresos, se corrobora la seducción del cliente mediante los artificios del mundo de la burbuja. Visto así el espacio urbano, carecería de "espacios del bien" yuxtapuestos a "espacios del mal". Es una diferenciación bien captada en la clasificación binaria de los "sistematizados", o adaptados al sistema y los otros, o el resto (Sacristán y Roca, 2007). Los estereotipos apoyados por el cine, la televisión y la propaganda inmobiliaria han codificado el espacio "bueno" como el iluminado, despejado, limpio, claro, vigilado, de armonía social, con apariencia física funcional de las construcciones y pavimentos, concurrido pero desahogado, amplio y ajardinado, en suma, es habitable (de éstos unos cuantos ejemplos en el cine serían American Beauty, Big Fish, Blue Velvet, Truman Show).

El espacio "malo" concentra datos opuestos: es oscuro, estrecho, confuso, contaminado, con interferencias visuales, construcciones deterioradas, maleza, graffitis y gente disfuncional sucia, con vestuario tribal, enfermos, homosexuales, prostitutas-, es criminalizado (véase, por ejemplo, la ciudad Gótica de la serie Batman y las brillantes realizaciones Blade Runner y Sin City). El primero es seguro a la actividad urbana y al descanso placentero; el segundo sugiere la ociosidad insana, la agresión, el atractivo vértigo de lo desconocido. Ambos espacios son, por requerimiento de estereotipo, excluyentes. Reducida a la población que la construye y modifica, sería la ciudad una manufactura entendible en todos sus rincones, una colmena de buenos vecinos laboriosos que se repiten y viven en comunidad. Desde luego, los malos vecinos no están incluidos en la promoción.

\title{
2. Conclusión.
}

Se acabó la edad de la inocencia en la arquitectura. Por lo menos de la arquitectura amparada en la ambivalencia. De la intencionalidad según la lista de preceptos se ha pasado al pragmatismo de las circunstancias que exigen respuestas de la moda prevaleciente. El código de diseño sigue en manos del especialista, ahora supeditado a la simbólica vernácula bien cotizada que amolda el banco de fragmentos formales a los prototipos de ocasión, cohesionando las partes en función de un imaginario dado por hecho.

Los modernistas intentaron resolver el formalismo ecléctico mediante la abstracción, los postmodernos atienden el vacío de la forma con derroche figurativo e hiperrealismo; aquéllos esgrimieron un proyecto de vida colectiva, éstos se basan en las aspiraciones de la individualización.

Esta condición define de entrada una tipología simple, a mayor disposición económica corresponde la construcción con mayor área, calidad, ostentación, equipamiento público, dispositivo de seguridad y símbolos. Pero en último término, así como se reparten los símbolos de tradiciones recién adoptadas, también se apropian los emblemas del espacio sin riesgo. La paradoja es que la abundancia figural no llena vacío alguno, sólo recompone el objeto visual. 
Resta, pues, deconstruir el vecindario y apropiarlo de acuerdo al momento y el lugar para responder al reclamo de pertenencia. El estilo de vida amable de los grupos sociales y compatible con la ciudad no se endosa con una forma construida, sino con la moda.. La arquitectura como simulacro de un mundo irrepetible no resuelve el desafío, pero sí enfatiza el apremio de abrir nuevos umbrales en el territorio a la vez que densificar y rescatar los intersticios de la ciudad heredada.

\section{Bibliografía}

Baudrillard, Jean. El intercambio simbólico y la muerte (1976). Caracas: Monte Ávila Latinoamericana, 1992.

Baudrillard, Jean. Cultura y simulacro (1978). Barcelona: Cairos, 2002.

Bordwell, David. Una mirada veloz. El estilo visual en el Hollywood de hoy. Letras Libres, 2004, Año VI, núm. 61: Cine sin límites, pp. 16-22.

Featherstone, Mike. Cultura de consumo y posmodernismo. Buenos Aires: Amorrortu, 1991.

Félix, Humberto. Tijuana la horrible. Entre la historia y el mito. Tijuana: El Colegio de la Frontera Norte y Libros Península, 2003.

Foucault, Michel. Esto no es una pipa. Ensayo sobre Magritte (1973). Barcelona: Anagrama, 1981.

Jameson, Fredric. Teoría de la postmodernid@d (1991), Valladolid: Trotta, 1996.

Maffesoli, Michel. Una sensibilidad primitiva. Estudios Sociológicos, 2004, Vol. XXII, núm. 66, pp. 541-556.

Sacristan, Irune y Roca, Joseph. Ciudad ensimismada, islarios defensivos frente a la otredad. ACE: Architecture, City and Environment = Arquitectura, Ciudad y Entorno (en línea), 2007, Any II, núm. 5, octubre (consulta: 25/01/2008), pp. 599-610. Disponible en: http://wwwcpsv.upc.es/ace/Articles-n5/numero5 pdf/DEF19 IRUNE.pdf>. ISSN - 1886-4805).

Silvestro, José María y Roca, Joseph. La ciudad como lugar. ACE: architecture, city and environment $=$ arquitectura, ciudad y entorno (en línea), 2007, vol.1, núm. 3. (Consulta: 25/01/2008), pp. 400-411. Disponible en: <http://www-cpsv.upc.es/ace/Articlesn3/29 silvestro.pdf>. ISSN 1886-4805. 